\title{
Diversity of Aerobic Bacteria Isolated from Oral and Cloacal Cavities from Free-Living Snakes Species in Costa Rica Rainforest
}

\author{
Allan Artavia-León, ${ }^{1}$ Ariel Romero-Guerrero, ${ }^{1,2}$ Carolina Sancho-Blanco, ${ }^{1}$ \\ Norman Rojas, ${ }^{3}$ and Rodolfo Umaña-Castro ${ }^{1}$ \\ ${ }^{1}$ Laboratorio de Análisis Genómico, Escuela de Ciencias Biológicas, Universidad Nacional, 86-3000 Heredia, Costa Rica \\ ${ }^{2}$ Laboratorio de Biología Molecular, Universidad de Costa Rica, Sede del Atlántico, Turrialba, Costa Rica \\ ${ }^{3}$ Centro de Investigación en Enfermedades Tropicales, Facultad de Microbiología, Universidad de Costa Rica, San José, Costa Rica
}

Correspondence should be addressed to Rodolfo Umaña-Castro; rodolfo.umana.castro@una.cr

Received 5 April 2017; Revised 28 June 2017; Accepted 6 July 2017; Published 20 August 2017

Academic Editor: Giovanni Colonna

Copyright (C) 2017 Allan Artavia-León et al. This is an open access article distributed under the Creative Commons Attribution License, which permits unrestricted use, distribution, and reproduction in any medium, provided the original work is properly cited.

Costa Rica has a significant number of snakebites per year and bacterial infections are often complications in these animal bites. Hereby, this study aims to identify, characterize, and report the diversity of the bacterial community in the oral and cloacal cavities of venomous and nonvenomous snakes found in wildlife in Costa Rica. The snakes where captured by casual encounter search between August and November of 2014 in the Quebrada González sector, in Braulio Carrillo National Park. A total of 120 swabs, oral and cloacal, were taken from 16 individuals of the Viperidae and Colubridae families. Samples were cultured on four different media at room temperature. Once isolated in pure culture, colonies were identified with the VITEK ${ }^{\circledR} 2 \mathrm{C}$ platform (bioMérieux). In order to test the identification provided on environmental isolates, molecular analyses were conducted on 27 isolates of different bacterial species. Specific 16S rDNA PCR-mediated amplification for bacterial taxonomy was performed, then sequenced, and compared with sequences of Ribosomal Database Project (RDP). From 90 bacterial isolates, 40 different bacterial species were identified from both oral and cloacal swabs. These results indicate the diversity of opportunistic pathogens present and their potential to generate infections and zoonosis in humans.

\section{Introduction}

Costa Rica is one of the countries with the highest rates of biodiversity per $\mathrm{km}^{2}$. It includes 143 species of snakes described. Within them, some species are venomous and potentially life-threatening to animals and humans: five species of coral snakes (family Elapidae, subfamily Elapinae), sixteen of pit vipers, such as Bothrops asper and Bothriechis schlegelii (family Viperidae, subfamily Crotalinae), and a sea snake (family Elapidae, subfamily Hydrophiinae) [1].

The family Colubridae, considered as nonvenomous, holds approximately 104 species like Sibon longifrenis (subfamily Dipsadinae) and Oxybelis brevirostris (subfamily Colubrinae) $[2,3]$.
In tropical regions, snakebites are important health problems [4]. Only in Central America, approximately 4000 snakebites have been registered per year, being the agricultural workers and/or rural residents the most affected $[5,6]$. In Costa Rica, the average of snakebites was 504 reports per year during 1990 to 2000 [7]. The study of these animals has focused greatly on poisonous species for their medical interest, since they are responsible for a significant number of snakebite incidents in the country [8].

During the period 1990-2000, a total of 5550 snakebite accidents were reported in hospitals and other health centers in Costa Rica. High variation was observed in the number of cases per year, ranging from 423 (1999) to 590 (1992). No trend was observed in the absolute number of snakebites 
over time averaging 504 reports per year [7]. However, the bacterial infections are often secondary complications of wounds to animal bites, and it has been determined that pathogenic microorganisms responsible for infection are also present in the oral flora of the biting animal $[9,10]$.

It has been established that the ingested diet and its oral flora directly influence the oral microbiota of the snakes. It has been proposed that cloacal flora of the prey animals can be found in the oral cavity of the snakes, due to the prey defecating by the time it is ingested [9, 11]. Despite the influence of associations of bacteria and snakes and the influence of these bacteria on humans, there are few studies on the characterization and distribution of these microorganisms [12]. However, some bacterial distributions, including some Gram-positive bacteria such as Staphylococcus sp., have been confirmed in snakes biota. They are predominant in the oral cavities of healthy snakes but Gram-negative bacteria such as Pseudomonas aeruginosa, Providencia rettgeri, and Pseudomonas maltophilia (currently Stenotrophomonas maltophilia) are predominant in the oral cavities of snakes with stomatitis $[12,13]$. Other members belonging to the family Enterobacteriaceae can cause respiratory diseases in humans [12]. Also some species of the genus Stenotrophomonas sp., for example, S. maltophilia, may induce diseases such as endocarditis, sepsis, meningitis, peritonitis, soft tissue infections, and wounds [14].

The aim of this study is to identify, characterize, and report the diversity of the bacterial community in the oral and cloacal cavities of venomous and nonvenomous snakes found in wildlife into the rainforest of central volcanic mountain range, Costa Rica.

\section{Material and Methods}

2.1. Area of Study. The Quebrada González sector forms part of the vast Braulio Carrillo National Park located in $10^{\circ} 09^{\prime} 39.88^{\prime \prime} \mathrm{N} y 83^{\circ} 56^{\prime} 13.97^{\prime \prime} \mathrm{O}$. The forest located in the area is montane rainforest transitioning to tropical moist basal. It has been registered up to $6375,5 \mathrm{~mm}$ of annual precipitation and an average temperature of $24^{\circ} \mathrm{C}$. On the other hand, the site's average elevation is $514,4 \pm 81,3 \mathrm{~m}$ and has strong inclines in most of its area [15]. The forest composition varies from secondary to mature forests, including open areas formed by the Sucio river [15-17]. Also present are various important tributaries like Quebrada González that have a constant flow throughout the year, making the water source abundant in the sector $[18,19]$.

2.2. Sample Collection. The snakes were captured between August and November, 2014. On each field trip, sampling took place in the morning (7 a.m.-11 a.m.) and at night (7 p.m. -11 p.m.); since there are more active individuals $[2,19]$, search was conducted with an intensive search technique for a casual encounter [20], looking for individuals on the ground, on leaf litter, and on top of vegetation. Snakes were captured with the assistance of herpetological tongs and identified to a species level. A total of 120 swabs, oral and cloacal, were taken from 16 individuals of both Viperidae and Colubridae families. Samples were taken and immediately cultured on four different media at room temperature; Mannitol-salt agar (MSA), MacConkey agar (MCA), Salmonella-Shigella agar (SSA), and blood agar (BA). Cultures were taken to the laboratory on a 24- to 48-hour period; bacterial isolates were separated by morphology and Gram staining. Once grown and pure, cultures were inoculated on blood agar or trypticase soy agar for further processing. After $24 \mathrm{~h}$, these isolates were taken to the Laboratorio de Bacteriología Médica, Facultad de Microbiología, Universidad de Costa Rica, to be identified and submitted to antibiotic susceptibility testing (AST) with the VITEK 2C platform (bioMérieux). To verify the identification provided on environmental isolates, molecular analyses were conducted on 27 isolates of different bacterial species.

2.3. Total DNA Extraction and PCR. Total genomic extraction was performed of bacterial pellets after strong centrifugation using STES buffer (0.2 M Tris-HCL, $0.5 \mathrm{M} \mathrm{NaCl}$, $0.01 \mathrm{M}$ EDTA, 1\% SDS) and standard phenol/chloroform extraction method was performed [21]. Specific 16 S rDNA PCRmediated amplification for bacterial taxonomy was executed with the following primers: $5^{\prime}$-AGAGTTTGATCMTGGCTCAG-3' and 5'-GTTACCTTGTTACGACTT-3' [22]. Polymerase chain reactions were arranged at a $20 \mu \mathrm{l}$ final volume with PCR Master Mix (2x) (Thermo Scientific ${ }^{\circledR}$ ), $0.3 \mu \mathrm{M}$ forward and reverse primer, and $100 \mathrm{ng}$ of bacterial genomic DNA template. Thermocycling parameters for the gene fragment amplification consisted of initial denaturalization at $95^{\circ} \mathrm{C}$ for $5 \mathrm{~min}$, followed by 36 cycles of denaturalization $\left(95^{\circ} \mathrm{C}, 45 \mathrm{~s}\right)$, annealing $\left(58-62^{\circ} \mathrm{C}, 1 \mathrm{~min}, 30 \mathrm{~s}\right)$, extension $\left(72^{\circ} \mathrm{C}, 1 \mathrm{~min}, 15 \mathrm{~s}\right)$, and final extension step at $72^{\circ} \mathrm{C}$ for $7 \mathrm{~min}$. PCR reactions were conducted on a thermal cycler (Proflex PCR System; Applied Biosystems, Life Technologies, USA). Amplicons were visualized by agarose gel electrophoresis (1.5\%) in TBE 1x (Tris-base, boric acid, EDTA, pH 8), stained with GelRed ${ }^{\circledR}$ (Biotium). GeneRuler $1 \mathrm{~kb}$ plus DNA Ladder (Thermo Scientific) was used as size marker. Molecular biology grade water (Ambion ${ }^{\circledR}$ ) was used as negative control.

2.4. Sequencing and Bioinformatics Analysis. PCR products were purified by isopropanol precipitation and quantified with a NanoDrop 2000 spectrophotometer (Thermo Scientific) and used for direct DNA sequencing. Partial gene fragments of 16S rRNA were sequenced, using the same amplification primer (BigDye Terminator ${ }^{\circledR}$ V3.1, Applied Biosystems), according to manufacturer's instructions. The resulting products were purified with the Xterminator Kit (Applied Biosystems) and then run on DNA multicapillary sequencer (Model 3130, Applied Biosystems) at the Laboratorio de Análisis Genómico, Escuela de Ciencias Biológicas, Universidad Nacional, Costa Rica. Recovered sequences were edited using Geneious ${ }^{\circledR}$ R9 version (Biomatters Ltda), analyzed with BLASTn algorithm [23] at the NCBI (http://www.ncbi.nlm.nih.gov/blast) with the $16 \mathrm{~S}$ ribosomal DNA sequences (Bacteria and Archaea) database, and compared with other previously published sequences. On the other hand, all bacterial $16 \mathrm{~S}$ ribosomal DNA sequences 
obtained were compared with sequences of Ribosomal Database Project (RDP) database using the Seq Match algorithm, parameter S_ab score (http://rdp.cme.msu.edu/) for sequence similarities searches to confirm bacterial identity [24]. Our nucleotide sequence data for 16S rRNA gene was deposited in GenBank (https://www.ncbi.nlm.nih.gov/genbank/) under accession numbers KY963324 to KY963344.

Local sequences and ones obtained at GenBank database were dereplicated by USEARCH v7.0 software [25] through cluster fast command application (under a threshold identity 0.99000$)$. Then, nonduplicates clusters sequences were aligned using MUSCLE algorithm [26] with default parameters. Phylogenetic tree was performed using maximum likelihood (ML) by raxmlGUI v.7.4.2 [27, 28] software through GTR-GAMMA substitution model and 1000 rapid bootstrap inferences. The consensus trees were visualized and edited in FigTree 1.4 program [29].

\section{Results}

A total of 90 bacterial isolates (from 120 cloacal and oral swabs) were recovered from 16 individuals of several species including Bothrops asper, Bothriechis schlegelii, Leptodeira septentrionalis, Sibon longifrenis, Oxyrhopus petolarius, Oxybelis brevirostris, and Imantodes cenchoa. Overall 40 different bacterial species (12 families) were identified by VITEK approach from both oral and cloacal swabs (Table 1). Both Viperidae species, B. asper and B. schlegelii, isolates had the most different bacterial morphotype with 32 and 18, respectively, followed by $S$. longifrenis with $13, O$. petolarius with 9, L. septentrionalis and I. cenchoa with 7, and finally O. brevirostris with 4 isolates (data not shown). About the distinctive colony phenotypes, 47 of the isolates were found in oral swabs and 43 on the cloacal swabs. From all the isolates identified with the VITEK platform, none are certainly exclusive from either oral or cloacal swabs. However, the few isolates that were identified as a unique bacterial species in either cavity were identified only once. Amongst these unique genera, we can find Bordetella, Salmonella, Elizabethkingia, Sphingomonas, and Rhizobium.

In the family Enterobacteriaceae, a general resistance pattern was found for ampicillin and cephalothin, being susceptible to these antibiotics E. coli and R. ornithinolytica, respectively. On the other hand, they were widely susceptible to various antibiotics: $\mathrm{PpC} / \mathrm{Tzba}, \mathrm{Cfa}, \mathrm{Cft}, \mathrm{Cfe}, \mathrm{Imi}, \mathrm{Mer}$, Ami, Gen, and Cip2. The only exception is $H$. alvei showing resistance to the combination of $\mathrm{PpC} / \mathrm{Tzba}$. The second family with more representatives in our AST was Staphylococcaceae. It was widely susceptible to most of the antibiotics; however, S. saprophyticus and S. warneri were the only species with resistance to antibiotics. Additionally, several bacterial isolates identified as opportunistic pathogens show resistance to different antibiotics, for example, Aeromonas hydrophila (Amp and Amp/Sbt), Achromobacter xylosoxidans (Amp/Sbt, Gen, Na, and Nit) Serratia marcescens (Cef and Nit), Elizabethkingia meningoseptica (Amp, Amp/Sbt, PpC/Tzba, Gen, and Nit), and Pseudomonas fluorescens (Amp, Amp/Sbt, Na, and Nit) (Table 2).
In the phylogenetic structure obtained for Gram-positive bacteria, we observe clustering of four families: Micrococcaceae, Paenibacillaceae, Bacillaceae, and Staphylococcaceae. On this tree, conflict between identification analyses is shown for isolates $\mathrm{SlO} 2914$ and $\mathrm{LsO} 2847$. For the Gram-negative bacteria phylogenetic tree, our sequences clustered majorly in three families: Xanthomonadaceae, Pseudomonadaceae, and Enterobacteriaceae. In this topology, we have more taxonomic inconsistencies, mainly on the Enterobacteria, concerning these isolates: $\mathrm{BsO} 3054, \mathrm{SlO} 2981, \mathrm{SlC} 2883, \mathrm{SlO} 2982$, $\mathrm{BaO} 2749$, and LsC2975. However, more than 65 percent of the isolates analyzed with biochemical and molecular approach turned out in consistent identification at the genera level (Figure 1).

\section{Discussion}

Differences in habitat, predation strategies, and the type of prey can provide an explanation for the high variation in bacterial flora [30]. A marked trend on cloacal and oral isolates is not very well defined in our results. A factor that could influence the bacterial composition on oral or cloacal cavities is feeding habits. At the time of sampling, it is not known how recent has the snake eaten, which could explain why no differences on the number of isolates between terrestrial and arborous species were found. At the same time, it explains the lack of significant difference on oral and cloacal isolates. Another factor to consider is that snakes are very active and most species are not confined to a certain habitat [2].

Snake bites have a high rate of infection because of Gramnegative bacteria [31]. This is due to their eating habits, where the prey head is ingested first, leaving a colonization of fecal flora on the oral cavity. This also could explain the higher amount of enterobacterial isolates found in the mouth of the individuals sampled.

Providencia sp. was found in the oral cavity of captive snakes from Costa Rica [32]. Another study on Bothrops jararaca reported several species of bacteria from the oral cavity including Providencia rettgeri, Staphylococcus aureus, Salmonella typhimurium, Citrobacter sp., and Morganella morganii [33]. This finding coincided with our study, except that we found the last three genera on the cloaca not in the mouth. On a study carried out by Ferreira Junior et al. (2009) [34], they indicate the presence of Salmonella enterica and M. morganii in the oral cavity of rattlesnakes, and also Citrobacter freundii was found in the cloaca. In nonvenomous snakes, such as Python regius and Clelia scyntalina, Serratia marcescens, $M$. morganii, and $C$. freundii and other species in the oral cavity were identified [35]. On the other hand, Elaphe quatuorlineata (Colubridae) sampled at their natural habitats have shown bacterial isolates mainly of the genera Serratia, Stenotrophomonas, Escherichia, Aeromonas, Pseudomonas, Staphylococcus, and Bacillus [36].

Inconsistencies in bacterial identification between $16 \mathrm{~S}$ rRNA sequencing and biochemical analyses conducted on the VITEK platform could be due to several factors. On a clinical study, 92\% identity fidelity with a $16 \mathrm{~S}$ sequencing 
TABLE 1: Bacteria isolates from oral and cloacal cavities of Bothrops asper (Ba), Bothriechis schlegelii (Bs), Leptodeira septentrionalis (Ls), Sibon longifrenis (Sl), Oxyrhopus petolarius (Op), Oxybelis brevirostris (Ob), and Imantodes cenchoa (Ic) analyzed and identified by VITEK biochemical approach and SeqMatch algorithm (RDP database). Isolates that were not sequenced are denoted with ND (no data).

\begin{tabular}{|c|c|c|c|}
\hline Isolate & Bacterial identification (VITEK \%) & SeqMatch identification (\%) & Family \\
\hline $\mathrm{BaC} 3280$ & Aeromonas hydrophila (98) & Aeromonas hydrophila (100) & Aeromonadaceae \\
\hline OpO3329 & Bordetella hinzii (99) & ND & Alcaligenaceae \\
\hline OpC3328 & Achromobacter xylosoxidans (96) & Achromobacter xylosoxidans (94) & Alcaligenaceae \\
\hline $\mathrm{BaO} 2767$ & Bacillus megaterium (90) & Bacillus megaterium (100) & Bacillaceae \\
\hline $\mathrm{LsO} 2847$ & Bacillus cereus $(97)$ & Staphylococcus sp. (87) & Bacillaceae \\
\hline $\mathrm{IcO} 2956$ & Bacillus licheniformis (89) & Bacillus cereus (100) & Bacillaceae \\
\hline BsC2959 & Bacillus subtilis (87) & Bacillus licheniformis (100) & Bacillaceae \\
\hline IcC3322 & Bacillus mycoides (95) & ND & Bacillaceae \\
\hline $\mathrm{BaO} 2749$ & Pantoea sp.(98) & Citrobacter sp. (96) & Enterobacteriaceae \\
\hline SlC2883 & Escherichia coli (88) & Citrobacter freundii (97) & Enterobacteriaceae \\
\hline LsC2848 & Morganella morganii morganii (99) & Citrobacter sp. (90) & Enterobacteriaceae \\
\hline $\mathrm{BsO} 2917$ & Serratia marcescens (99) & Serratia sp. (96) & Enterobacteriaceae \\
\hline IcC2910 & Enterococcus faecalis (99) & ND & Enterobacteriaceae \\
\hline IcO2913 & Hafnia alvei (99) & $N D$ & Enterobacteriaceae \\
\hline LsC2975 & Citrobacter freundii (99) & Kluyvera ascorbata (98) & Enterobacteriaceae \\
\hline $\mathrm{BaO} 2743$ & Providencia rettgeri (99) & ND & Enterobacteriaceae \\
\hline $\mathrm{BaC} 2744$ & Salmonella enterica diarizonae (97) & $N D$ & Enterobacteriaceae \\
\hline $\mathrm{BaC} 3287$ & Serratia liquefaciens (99) & ND & Enterobacteriaceae \\
\hline $\mathrm{BaC} 3290$ & Citrobacter braakii (99) & ND & Enterobacteriaceae \\
\hline $\mathrm{BsC} 2920$ & Yokenella regensburgei (95) & Yokenella regensburgei (86) & Enterobacteriaceae \\
\hline IcC3357 & Proteus hauseri (94) & $\mathrm{ND}$ & Enterobacteriaceae \\
\hline OpC3327 & Raoultella ornithinolytica (94) & ND & Enterobacteriaceae \\
\hline $\mathrm{SlO} 2982$ & Elizabethkingia meningoseptica (99) & Citrobacter sp. (95) & Flavobacteraceae \\
\hline BsO3055 & Kocuria kristinae $(94)$ & ND & Micrococcaceae \\
\hline SlO3051 & Micrococcus luteus (97) & Microbacterium sp.(97) & Micrococcaceae \\
\hline $\mathrm{BaO} 3269$ & Kocuria varians (96) & Kocuria palustris (91) & Micrococcaceae \\
\hline OpC3324 & Kocuria rhizophila (99) & Kocuria rhizophila (95) & Micrococcaceae \\
\hline $\mathrm{SlO} 2981$ & Acinetobacter lwoffii (89) & Halomonas johnsoniae (94) & Moraxellaceae \\
\hline BsC2971 & Paenibacillus glucanolyticus (96) & Paenibacillus glucanolyticus (99) & Paenibacillaceae \\
\hline $\mathrm{SlO} 2980$ & Pseudomonas fluorescens (90) & Pseudomonas fluorescens (94) & Pseudomonaceae \\
\hline BsO3054 & Pseudomonas putida (99) & Stenotrophomonas maltophilia (75) & Pseudomonaceae \\
\hline $\mathrm{BaO} 3286$ & Rhizobium radiobacter (99) & Rhizobium radiobacter (91) & Rhizobiaceae \\
\hline $\mathrm{BaC} 3354$ & Sphingomonas paucimobilis (86) & ND & Sphingomonadaceae \\
\hline $\mathrm{SlO} 2914$ & Staphylococcus saprophyticus (99) & Paenibacillus sp. (98) & Staphylococcaceae \\
\hline $\mathrm{BaO} 2955$ & Staphylococcus kloosii (99) & Staphylococcus sp. (99) & Staphylococcaceae \\
\hline SlC3049 & Staphylococcus xylosus (91) & Staphylococcus xylosus (99) & Staphylococcaceae \\
\hline $\mathrm{BsO} 2775$ & Staphylococcus sciuri (97) & Staphylococcus sciuri (98) & Staphylococcaceae \\
\hline $\mathrm{BaC} 3263$ & Staphylococcus arlettae (99) & Staphylococcus arlettae (82) & Staphylococcaceae \\
\hline $\mathrm{BsC} 2770$ & Staphylococcus warneri (93) & Staphylococcus pasteuri (99) & Staphylococcaceae \\
\hline SlC2885 & Stenotrophomonas maltophilia (99) & ND & Xanthomonadaceae \\
\hline
\end{tabular}

approach was obtained, while VITEK only resolved $52 \%$ of the samples [37]. In our case, some isolates could be difficult to identify due to lack of entries in the database. However, in almost all of the samples, percentages of identification from VITEK are above $90 \%$. Another factor that could be interfering is the lack of primer match suitable sites on the 16S rRNA for bacterial species level identification [38]; also the primers used (27f and 1492r) are widely known universal primers. This leads to a possible systematic underrepresentation of the matching phylogenetic group due to a difference in nucleotides [39].

Bacteria isolated from snakes on a zoo, such as Citrobacter sp., Enterobacter sp., Escherichia coli, Hafnia alvei, Morganella morganii, Proteus sp., Stenotrophomonas maltophilia, and Pseudomonas sp., could be opportunistic pathogens and generate nosocomial infections. Besides, Sphingomonas 


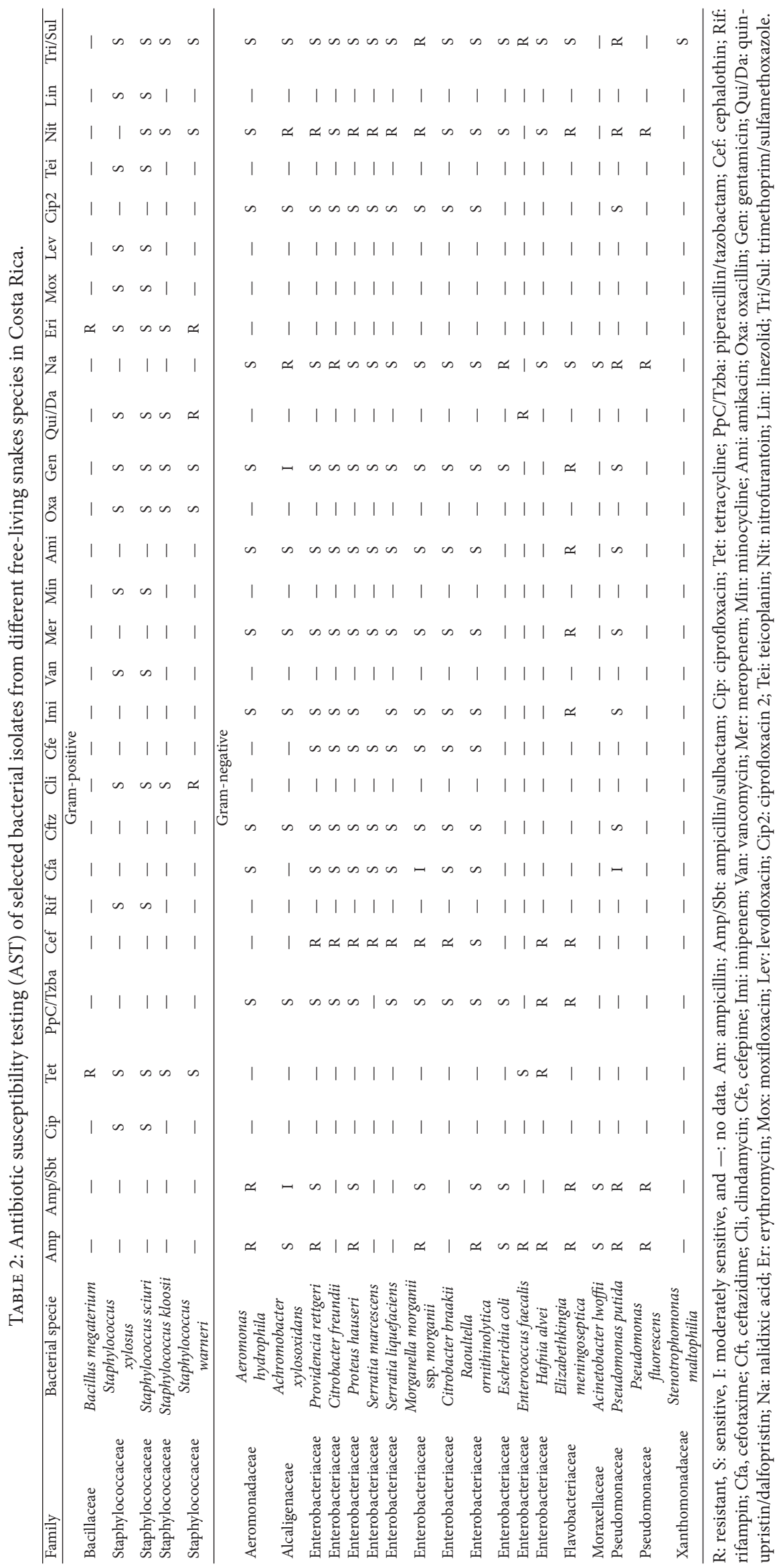




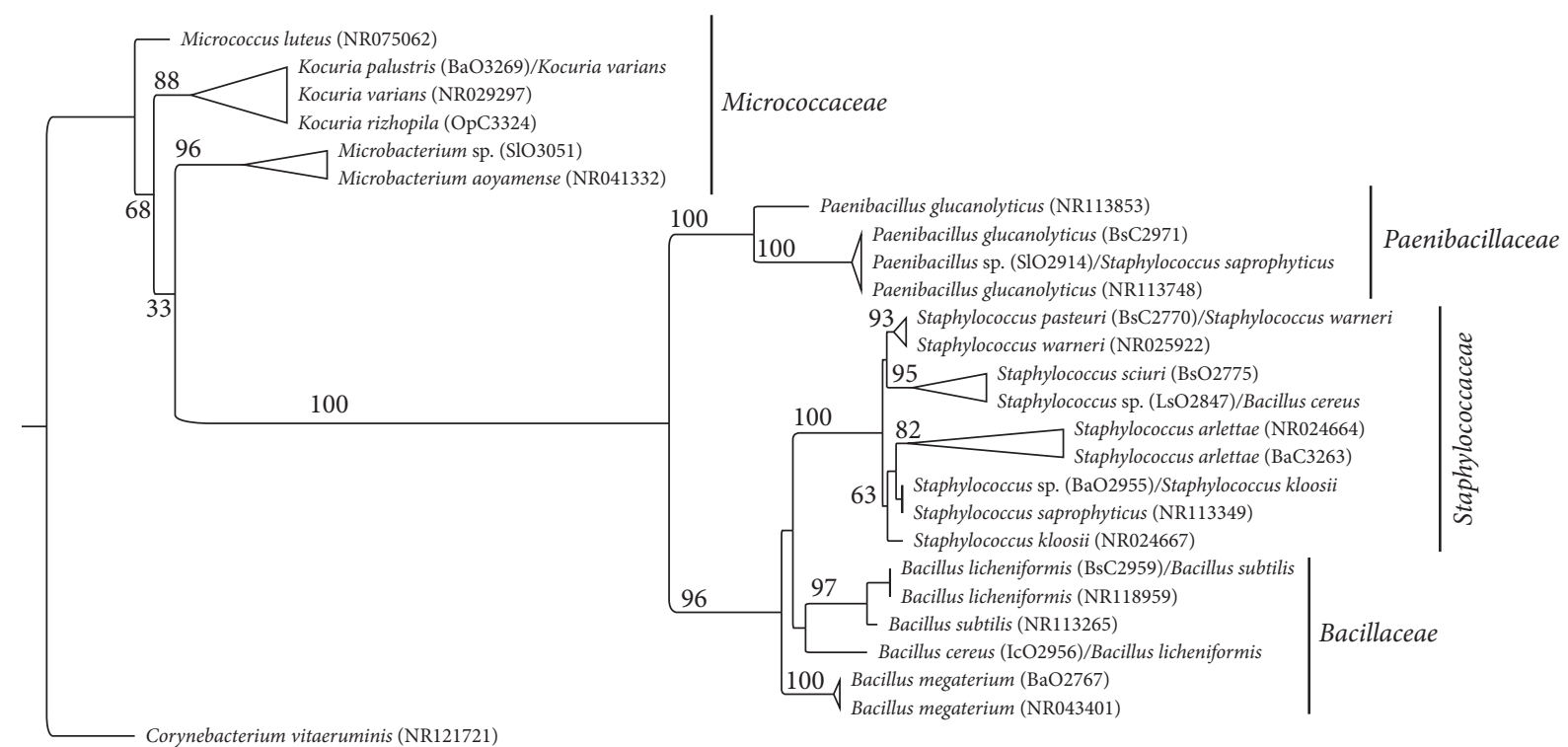

0.07

(a)

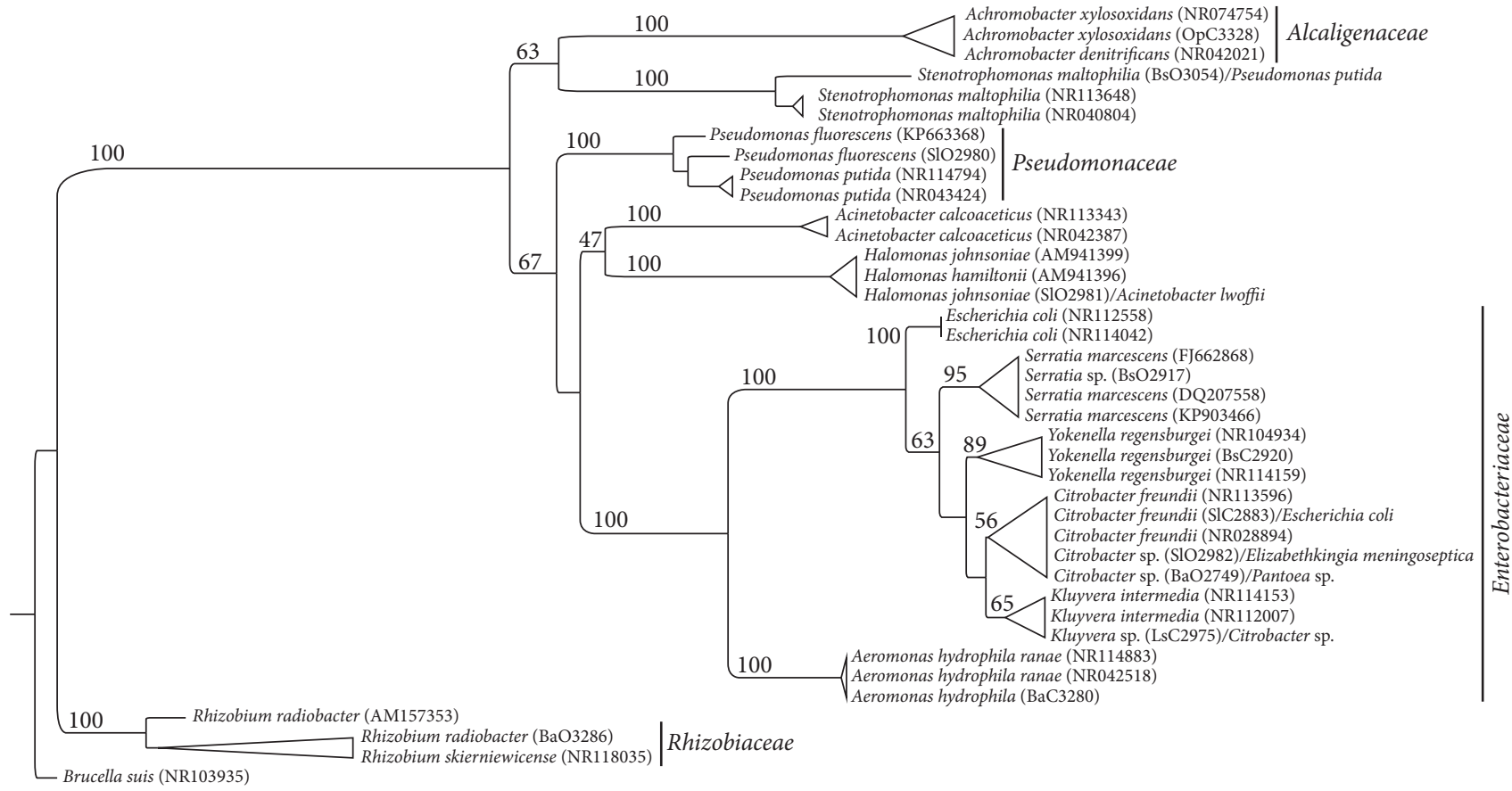

0.06

(b)

FIGURE 1: Phylogenetic position of local bacterial isolates by maximum-likelihood topology based on a partial sequence of the $16 \mathrm{~S}$ ribosomal RNA gene. (a) Gram-positive tree, outgroup Corynebacterium vitaeruminis. (b) Gram-negative tree, outgroup Brucella suis. The first identity shown in each branch was obtained by the SeqMatch algorithm; the latter identity was obtained by VITEK biochemical analyses. Branches with only one identity stand for congruence between both SeqMatch and VITEK. In parentheses, there is our local isolate code or GenBank accession number. 
paucimobilis has been associated with infections of the oral mucosa of humans [40]. On the other hand, pathogens like Enterococcus faecalis, Salmonella arizonae, and Staphylococcus lentus can generate zoonosis [12]. Similar bacterial genera were found compared to our results, where predominantly Staphylococcus, Pseudomonas, and Enterobacter match our findings [41].

Important to notice is the presence of $M$. morganii, a pathogen highly involved in abscess generation [30, 42]. The several species of Staphylococcus found can generate local infections and have been isolated in clinical cases [31]. Yokenella regensburgei has been known to generate septicemias from soft tissue infections, especially for immunocompromised hosts [43]. The capacity of Aeromonas hydrophila is well known to cause severe infections after snakebites [44]. Another species identified was Raoultella ornithinolyt$i c a$, a poorly described pathogen with rare cases of infection, with a high mortality rate reported $(20 \%)$. This pathogen can produce bacteremia, skin infections, and respiratory infections [45].

Finally, Elizabethkingia meningoseptica was identified, an opportunistic pathogen that could have serious consequences on humans, with a reported $24 \%$ mortality rate over 118 patients [46]. Although it was found on a nonvenomous species, it is fairly commonly distributed [2]. This pathogen has been previously isolated in dead amphibians with cataracts and showed severe consequences to the host [47].

The vast majority of isolates showed antibiotic sensitivity patterns typical of wild, nonexposed strains and several natural resistance mechanisms widely distributed in nature. Resistance patterns suggested natural mechanisms of antibiotic resistance, such as constitutive chromosomal AmpC beta-lactamases and cephalosporinases, common in genera such as Enterobacter, Citrobacter, Serratia, Proteus, Escherichia, and Morganella [48]. Probable evidences of QNR protein and efflux pumps could be present in Enterobacteria and Pseudomonas strains, according to their resistance to nalidixic acid, but not to quinolones [49]. Similarly, resistance mechanisms to erythromycin and tetracycline due to efflux pumps could be present in Gram-positive cocci isolates, as they are widespread $[50,51]$.

An important diversity of aerobic bacteria was isolated (40 different bacterial species) from oral and cloacal mucous membrane from wildlife snakes species. Also with similar findings, other studies looked at bacterial diversity in different reptiles like turtles [52] and Komodo dragons [53], corroborating our results. Even studies regarding fungal diversity [44] conclude that these findings should be considering in the clinical picture when treating these animal bites. Importantly, antibiotics most appropriate in the case of infection by these pathogens are reported as well as the resistance found in these wild strains.

In summary, to our knowledge herein, this is the first report of a survey that combines biochemical and molecular approaches that identifies aerobic bacterial communities isolated from free-living venomous and nonvenomous snakes from Costa Rican rainforests. We also obtained an antibiotic susceptibility test (AST) for bacterial clusters inhabiting the cavities of local serpents. Our results revealed that the majority of the 12 bacterial families could bring health complications after a snakebite.

\section{Conflicts of Interest}

The authors declare that there are no conflicts of interest regarding the publication of this paper.

\section{Acknowledgments}

The authors are very grateful to the group of colleagues working with snakes at Braulio Carrillo, especially Jonathan Vega, Daniel Ramírez, Alejandro Zuñiga, Mauricio de la O, and Wouter Baaijen, for their effort on collaborating with sampling. At the same time, the authors appreciate the vital support of all laboratories involved: Laboratory of Genomic Analyses (LAGEN), Laboratory of Biotechnology at National University, and the Laboratory of Medical Bacteriology, Faculty of Microbiology, University of Costa Rica. Finally, the authors appreciate all the work from laboratory staff, especially Abad Rodríguez and Silvia Mau who facilitated commodities when needed.

\section{References}

[1] B. Lomonte, J. Fernández, L. Sanz et al., "Venomous snakes of Costa Rica: Biological and medical implications of their venom proteomic profiles analyzed through the strategy of snake venomics," Journal of Proteomics, vol. 105, pp. 323-339, 2014.

[2] A. Solórzano, Serpientes de Costa Rica, Instituto Nacional de Biodiversidad, Santo Domingo de Heredia, Costa Rica, 2004.

[3] Y. Zheng and J. J. Wiens, "Combining phylogenomic and supermatrix approaches, and a time-calibrated phylogeny for squamate reptiles (lizards and snakes) based on 52 genes and 4162 species," Molecular Phylogenetics and Evolution, vol. 94, pp. 537-547, 2016.

[4] E. Hansson, M. Sasa, K. Mattisson, A. Robles, and J. M. Gutiérrez, "Using geographical information systems to identify populations in need of improved accessibility to antivenom treatment for snakebite envenoming in Costa Rica," PLoS Neglected Tropical Diseases, vol. 7, no. 1, Article ID e2009, 2013.

[5] J. M. Gutiérrez, "Snakebite poisoning in Latin America and the Caribbean: an integral view from a regional perspective," Boletin de Malariologia y Salud Ambiental, vol. 51, no. 1, pp. 1-16, 2011.

[6] R. Otero-Patiño, "Epidemiological, clinical and therapeutic aspects of Bothrops asper bites," Toxicon, vol. 54, no. 7, pp. 9981011, 2009.

[7] M. Sasa and S. Vazquez, "Snakebite envenomation in Costa Rica: a revision of incidence in the decade 1990-2000," Toxicon, vol. 41, no. 1, pp. 19-22, 2003.

[8] P. Saborío, M. González, and M. Cambronero, "Accidente ofídico en niños en Costa Rica: epidemiología y detección de factores de riesgo en el desarrollo de absceso y necrosis," Toxicon, vol. 36, no. 2, pp. 359-366, 1998.

[9] G. Zancolli, D. Mahsberg, W. Sickel, and A. Keller, "Reptiles as reservoirs of bacterial infections: real threat or methodological bias?” Microbial Ecology, vol. 70, no. 3, pp. 579-584, 2015. 
[10] G. Blandón, Flora Bacteriana Asociada a la Cavidad Bucal en Serpientes de la Familia Viperidae, Trabajo de Grado en Modalidad de Extensión, Universidad de Caldas, Manizales Centro de Investigación y Asesoría Ofidiológica. OPHIDIA, 2009.

[11] J. Iqbal, M. Sagheer, N. Tabassum, R. Siddiqui, and N. A. Khan, "Culturable aerobic and facultative anaerobic intestinal bacterial flora of black cobra (Naja naja karachiensis) in Southern Pakistan," ISRN Veterinary Science, vol. 2014, Article ID 878479, 5 pages, 2014.

[12] Y. S. Jho, D. H. Park, J. H. Lee, and Y. S. Lyoo, "Aerobic bacteria from oral cavities and cloaca of snakes in a petting zoo," Korean Journal of Veterinary Research, vol. 51, no. 3, pp. 243-247, 2011.

[13] S. Baron, "Pseudomonas," in Medical Microbiology, B. H. Iglewsk, Ed., chapter 27, University of Texas Medical Branch at Galveston, Galveston, Tex, USA, 4th edition, 1996.

[14] C. A. Sattler, E. O. Mason Jr., and S. L. Kaplan, "Nonrespiratory Stenotrophomonas maltophiliainfection at a children's hospital," Clinical Infectious Diseases, vol. 31, no. 6, pp. 1321-1330, 2000.

[15] P. Oviedo-Pérez and L. Fournier-Gutiérrez, "Caracterización de la avifauna del sector Quebrada González, Parque Nacional Braulio Carrillo, Costa Rica," Brenesia, vol. 69, pp. 25-33, 2008.

[16] R. Lücking, "Ecology of foliicolous lichens at the "Botarrama" trail (Costa Rica), a Neotropical rain forest. I. Species composition and its ecogeographical implications," Biotropica, vol. 31, no. 4, pp. 553-564, 1999.

[17] D. Vásquez, R. W. Flowers, and M. Springer, "Life history of five small minnow mayflies (Ephemeroptera: Baetidae) in a small tropical stream on the caribbean slope of Costa Rica," Aquatic Insects, vol. 31, no. 1, pp. 319-332, 2009.

[18] J. Schelhas and G. A. Sánchez-Azofeifa, "Post-frontier forest change adjacent to Braulio Carrillo National Park, Costa Rica," Human Ecology, vol. 34, no. 3, pp. 407-431, 2006.

[19] W. McDiarmid, Reptile Biodiversity: Standard Methods for Inventory and Monitoring, University of California Press, 2012.

[20] W. J. Sutherland, Ed., Ecological Census Techniques: A Handbook, Cambridge University Press, 2006.

[21] J. Sambrook and D. W. Russell, "Purification of nucleic acids by extraction with phenol: chloroform," Cold Spring Harbor Protocols, vol. 2006, no. 1, 2006.

[22] K. H. Wilson, R. B. Blitchington, and R. C. Greene, "Amplification of bacterial $16 \mathrm{~S}$ ribosomal DNA with polymerase chain reaction," Journal of Clinical Microbiology, vol. 28, pp. 19421946, 1990.

[23] S. F. Altschul, W. Gish, W. Miller, E. W. Myers, and D. J. Lipman, "Basic local alignment search tool," Journal of Molecular Biology, vol. 215, no. 3, pp. 403-410, 1990.

[24] J. R. Cole, B. Chai, R. J. Farris et al., "The ribosomal database project (RDP-II): sequences and tools for high-throughput rRNA analysis," Nucleic Acids Research, vol. 33, pp. D294-D296, 2005.

[25] R. C. Edgar, "Search and clustering orders of magnitude faster than BLAST," Bioinformatics, vol. 26, no. 19, pp. 2460-2461, 2010.

[26] R. C. Edgar, "MUSCLE: multiple sequence alignment with high accuracy and high throughput," Nucleic Acids Research, vol. 32, no. 5, pp. 1792-1797, 2004.

[27] A. Stamatakis, T. Ludwig, and H. Meier, "RAxML-III: A fast program for maximum likelihood-based inference of large phylogenetic trees," Bioinformatics, vol. 21, no. 4, pp. 456-463, 2005.
[28] D. Silvestro and I. Michalak, "RaxmlGUI: a graphical front-end for RAxML," Organisms Diversity and Evolution, vol. 12, no. 4, pp. 335-337, 2012.

[29] A. Rambaut, FigTree vl.4 2012-2014: Tree Figure Drawing Tool, http://tree.bio.ed.ac.uk/software/figtree.

[30] K. C. Shek, K. L. Tsui, K. K. Lam et al., "Oral bacterial flora of the Chinese cobra (Naja atra) and bamboo pit viper (Trimeresurus albolabris) in Hong Kong SAR, China," Hong Kong Medical Journal, vol. 15, no. 3, pp. 183-190, 2009.

[31] M. Morgan, "Hospital management of animal and human bites," Journal of Hospital Infection, vol. 61, no. 1, pp. 1-10, 2005.

[32] O. Arroyo, R. Bolaños, and G. Muñoz, "The bacterial flora of venoms and mouth cavities of Costa Rican snakes," Bulletin of the Pan American Health Organization, vol. 14, no. 3, pp. 280285, 1980.

[33] M. T. Jorge, J. S. de Mendonça, L. A. Ribeiro, M. L. da Silva, E. J. Kusano, and C. L. Cordeiro, "Bacterial flora of the oral cavity, fangs and venom of Bothrops jararaca: possible source of infection at the site of bite," Revista do Instituto de Medicina Tropical de Sao Paulo, vol. 32, no. 1, pp. 6-10, 1990.

[34] R. S. Ferreira Junior, A. K. Siqueira, M. V. Campagner et al., "Comparison of wildlife and captivity rattlesnakes (Crotalus durissus terrificus) microbiota," Pesquisa Veterinaria Brasileira, vol. 29, no. 12, pp. 999-1003, 2009.

[35] M. O. Babalola and J. A. Balogun, "The ecology and potential health risk of the oral microflora of python regius and clelia scyntalina," International Journal of Microbiology Research, vol. 5, no. 1, pp. 349-356, 2013.

[36] M. Lukač, D. Horvatek Tomić, Z. Mandac, S. Mihoković, and E. Prukner-Radovčić, "Oral and cloacal aerobic bacterial and fungal flora of free-living four-lined snakes (Elaphe quatuorlineata) from Croatia," Veterinarski Arhiv, vol. 87, no. 3, pp. 351-361, 2017.

[37] P. P. Bosshard, R. Zbinden, S. Abels, B. Böddinghaus, M. Altwegg, and E. C. Böttger, "16S rRNA gene sequencing versus the API $20 \mathrm{NE}$ system and the VITEK 2 ID-GNB card for identification of nonfermenting Gram-negative bacteria in the clinical laboratory," Journal of Clinical Microbiology, vol. 44, no. 4, pp. 1359-1366, 2006.

[38] Y.-C. Chiang, C.-Y. Yang, C. Li, Y.-C. Ho, C.-K. Lin, and H.-Y. Tsen, "Identification of Bacillus spp., Escherichia coli, Salmonella spp., Staphylococcus spp. and Vibrio spp. with 16S ribosomal DNA-based oligonucleotide array hybridization," International Journal of Food Microbiology, vol. 107, no. 2, pp. 131-137, 2006.

[39] J. A. Frank, C. I. Reich, S. Sharma, J. S. Weisbaum, B. A. Wilson, and G. J. Olsen, "Critical evaluation of two primers commonly used for amplification of bacterial 16S rRNA genes," Applied and Environmental Microbiology, vol. 74, no. 8, pp. 2461-2470, 2008.

[40] A. Santarelli, M. Mascitti, R. Galeazzi, A. Marziali, F. Busco, and M. Procaccini, "Oral ulcer by Sphingomonas paucimobilis: first report," International Journal of Oral and Maxillofacial Surgery, vol. 45, no. 10, pp. 1280-1282, 2016.

[41] Y. S. Jho, D. H. Park, J. H. Lee, S. Y. Cha, and J. S. Han, "Identification of bacteria from the oral cavity and cloaca of snakes imported from Vietnam," Laboratory Animal Research, vol. 27, no. 3, pp. 213-217, 2011.

[42] R. Dehghani, M. R. Sharif, R. Moniri, A. Sharif, and H. H. Kashani, "The identification of bacterial flora in oral cavity of snakes," Comparative Clinical Pathology, vol. 25, no. 2, pp. 279283, 2016. 
[43] T. Bhowmick and M. P. Weinstein, "A deceptive case of cellulitis caused by a Gram-negative pathogen," Journal of Clinical Microbiology, vol. 51, no. 4, pp. 1320-1323, 2013.

[44] R. Dehghani, A. Sharif, M. A. Assadi, H. Haddad Kashani, and M. R. Sharif, "Fungal flora in the mouth of venomous and nonvenomous snakes," Comparative Clinical Pathology, vol. 25, no. 6, pp. 1207-1211, 2016.

[45] P. Seng, B. M. Boushab, F. Romain et al., "Emerging role of Raoultella ornithinolytica in human infections: A series of cases and review of the literature," International Journal of Infectious Diseases, vol. 45, pp. 65-71, 2016.

[46] M. S. Hsu, C. H. Liao, Y. T. Huang et al., "Clinical features, antimicrobial susceptibilities, and outcomes of Elizabethkingia meningoseptica (Chryseobacterium meningosepticum) bacteremia at a medical center in Taiwan, 1999-2006," European Journal of Clinical Microbiology and Infectious Diseases, vol. 30, no. 10, pp. 1271-1278, 2011.

[47] Z.-Y. Xie, Y.-C. Zhou, S.-F. Wang et al., "First isolation and identification of Elizabethkingia meningoseptica from cultured tiger frog, Rana tigerina rugulosa," Veterinary Microbiology, vol. 138, no. 1, pp. 140-144, 2009.

[48] G. A. Jacoby, "AmpC $\beta$-lactamases," Clinical Microbiology Reviews, vol. 22, no. 1, pp. 161-182, 2009.

[49] A. Hernández, M. B. Sánchez, and J. L. Martínez, "Quinolone resistance: much more than predicted," Frontiers in Microbiology, vol. 2, p. 22, 2011.

[50] L. J. V. Piddock, "Clinically relevant chromosomally encoded multidrug resistance efflux pumps in bacteria," Clinical Microbiology Reviews, vol. 19, no. 2, pp. 382-402, 2006.

[51] R. Leclercq, "Mechanisms of resistance to macrolides and lincosamides: Nature of the resistance elements and their clinical implications," Clinical Infectious Diseases, vol. 34, no. 4, pp. 482492, 2002.

[52] J. C. M. Junior, M. Marinho, C. V. Táparo, J. B. da Costa, and H. L. T. Dias, "Enterobacterias en tortugas silvestres y cautivas del Amazonas, Podocnemis expansa (Testudines: Podocnemididae)," Revista de Biología Tropical, vol. 63, no. 4, pp. 1083-1089, 2015.

[53] E. J. C. Goldstein, K. L. Tyrrell, D. M. Citron et al., "Anaerobic and aerobic bacteriology of the saliva and gingiva from 16 captive Komodo dragons (Varanus Komodoensis): New implications for the bacteria as venom model," Journal of Zoo and Wildlife Medicine, vol. 44, no. 2, pp. 262-272, 2013. 

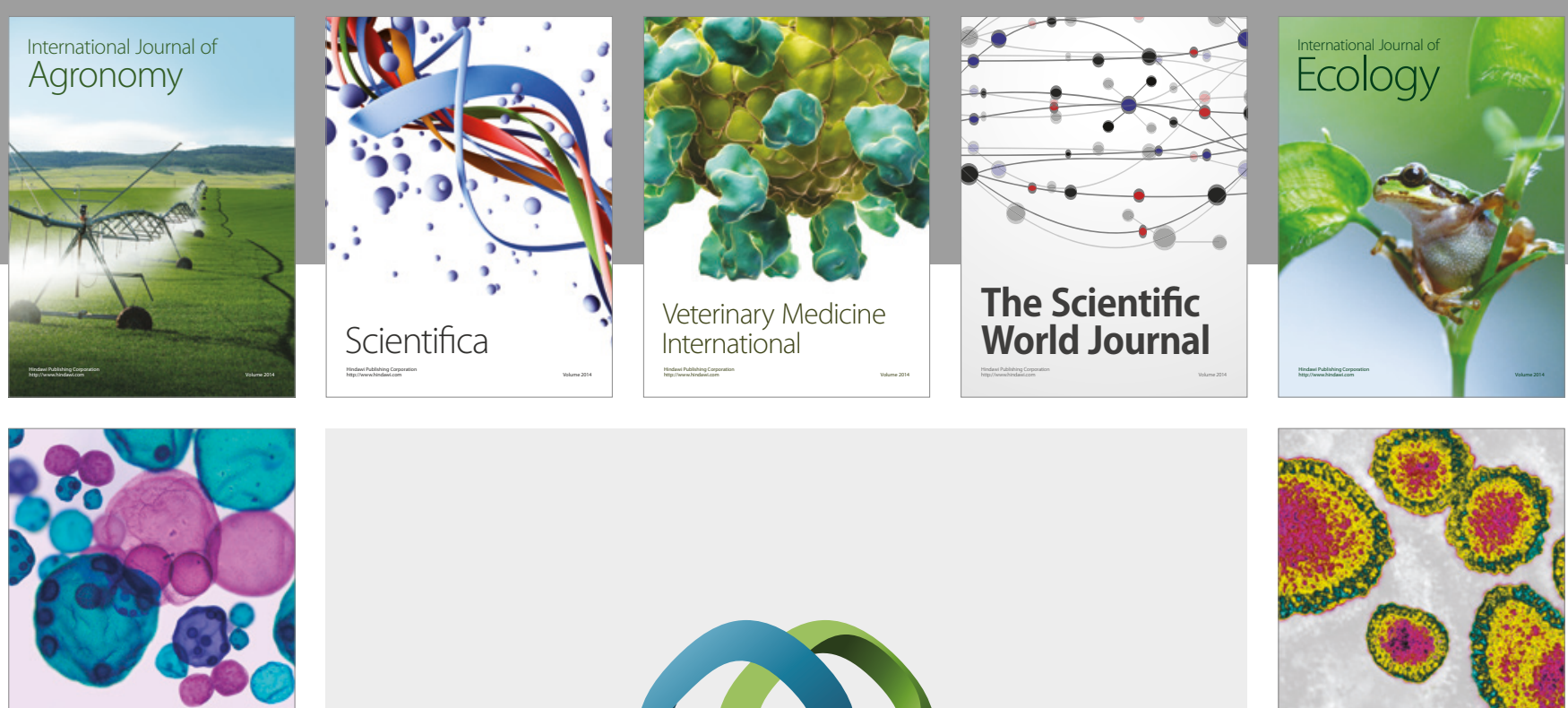

\section{International Journal of} Microbiology
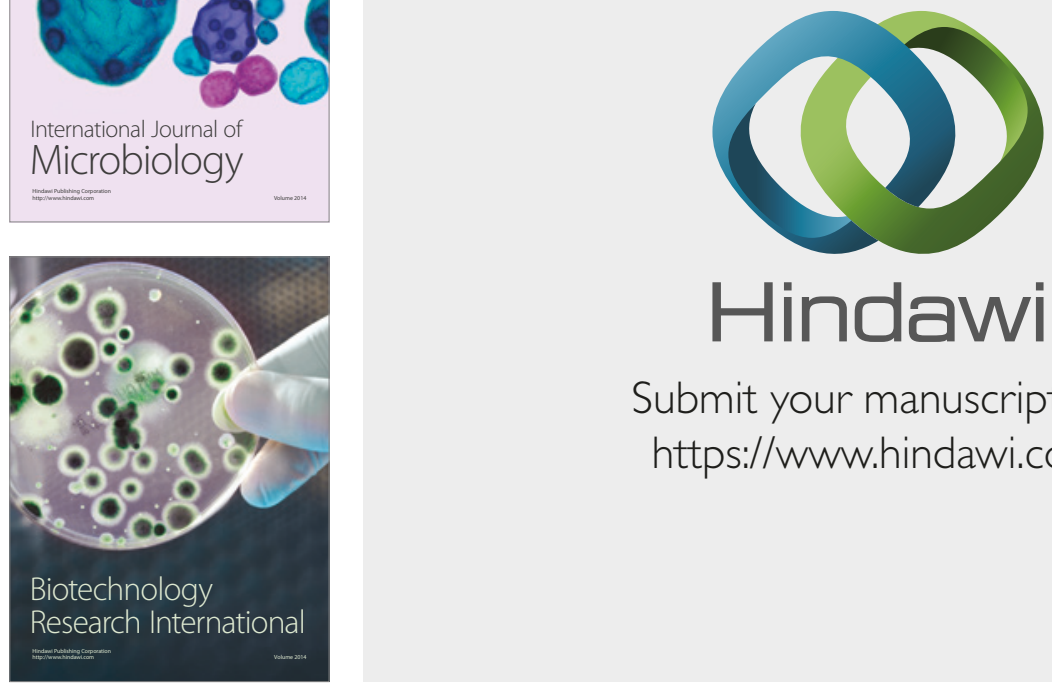

Submit your manuscripts at

https://www.hindawi.com
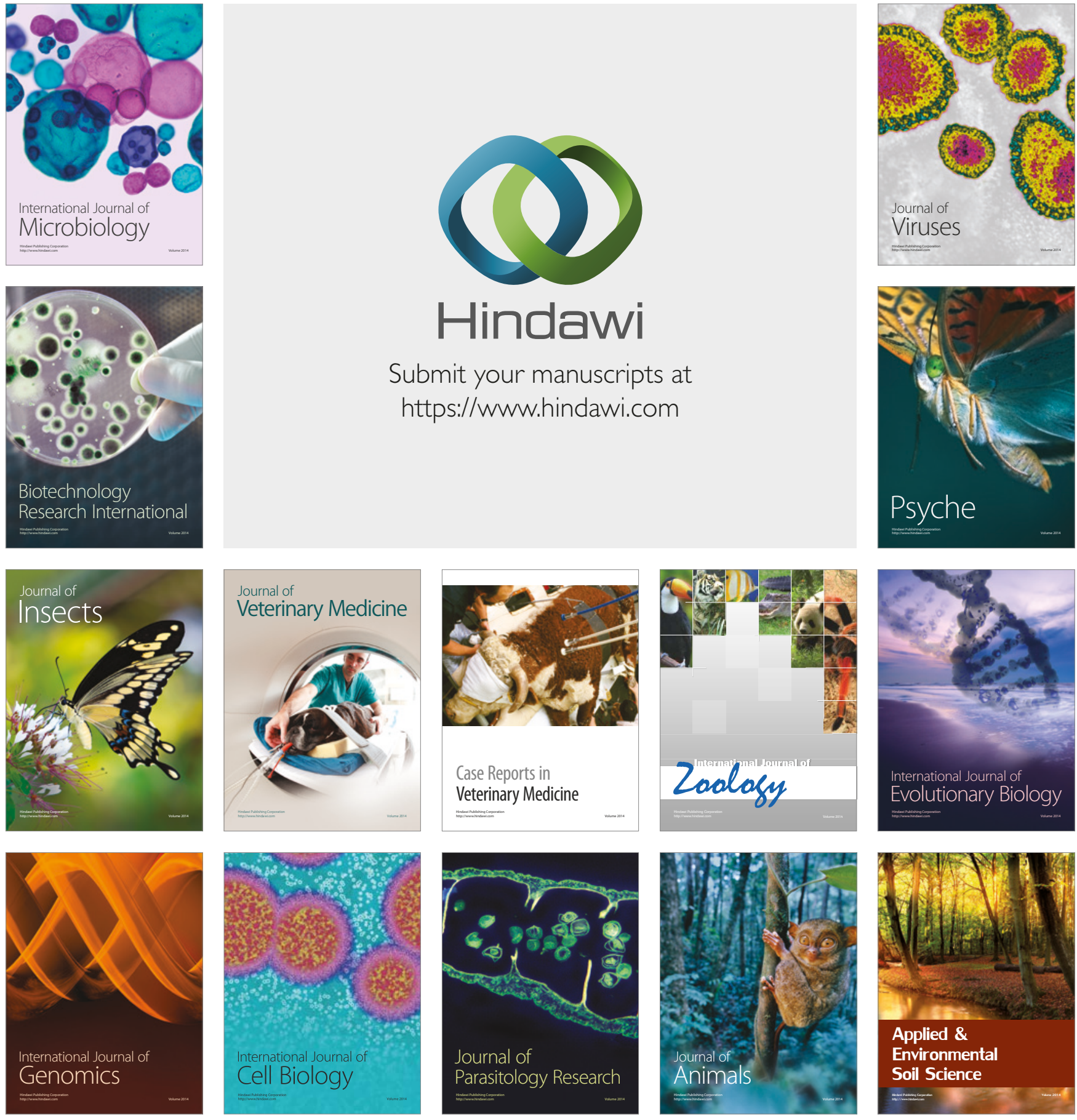